\section{Delivery options and risk of severe acute maternal morbidity}

In their CMAJ research article, Korb and colleagues ${ }^{1}$ caution women and obstetricians about the increased risks of severe acute maternal morbidity (SAMM) associated with cesarean delivery based on findings from their nonexperimental study. We have a few comments on concepts, methods and interpretation.

The conceptual concern relates to the study's primary analysis. Korb and colleagues ${ }^{1}$ evaluated cesarean and vaginal delivery as alternative modes of delivery; however, they are not management options available or offered in modern obstetrics. Instead, two management options are available: planned cesarean and planned vaginal delivery. ${ }^{2-4}$ Therefore, the only clinically relevant finding in this study ${ }^{1}$ is that there was no significant increase in the risk of SAMM after planned cesarean delivery (adjusted odds ratio $1.09,95 \%$ confidence interval 0.85-1.41).

The use of propensity score methods to control confounding by indication shows a disconnect between clinical and statistical issues: indication (for cesarean delivery) is a complex construct not amenable to accurate quantification, whereas propensity score analysis requires precise quantification of indication for complete control of confounding. ${ }^{5}$ Korb and colleagues ${ }^{1}$ provided no information on the indications for cesarean delivery, and their analysis controlled for some less relevant and some more relevant factors (e.g., country of birth and previous cesarean delivery) in lieu of controlling for confounding by the indication.

Confounding by indication represents an "intractable" problem in nonexperimental studies of intended effects, ${ }^{5}$ and attempts to address it in the design ${ }^{6}$ or analysis stage $^{1}$ typically result in residual confounding. Efficacy of therapy is, therefore, ideally assessed using randomized controlled trials (RCTs). Arguments about trial ethics notwithstanding, ${ }^{1}$ there have been 2 large RCTs comparing planned cesarean and planned vaginal delivery. ${ }^{3,4}$ Neither the Term Breech Trial $(n=2088)^{3}$ nor the Twin Births Study $(n=2804)^{4}$ showed any association between planned cesarean delivery and SAMM. Although these trials were limited in size (given the low frequency of SAMM), their findings (and those of less valid, nonexperimental studies) $)^{1,6}$ are consistent with a near-zero rate difference in SAMM between planned cesarean and planned vaginal delivery.

Cesarean delivery is a major surgical procedure with the potential for hemorrhage, sepsis and related complications. Nevertheless, progress in anesthesia and surgery has made this procedure relatively free of serious complications. All women who become pregnant need to be informed about the possibility of a small excess risk of serious short-term complications associated with cesarean delivery, ${ }^{6}$ and women planning large families should be informed also about the risk of serious long-term complications of cesarean delivery that may occur in subsequent pregnancies. ${ }^{7}$ However, these risks have to be balanced against alternative options with regard to both maternal and fetal or infant outcomes.

Although obstetricians are ideally placed to inform women about the risks and benefits of the different options for delivery, the ultimate valuation and choice has to be made by the pregnant woman. Respect for women's autonomy and informed choice are key pillars of modern obstetrics.

\section{K.S. Joseph MD PhD}

Professor, Department of Obstetrics and Gynaecology, School of Population and Public Health, University of British Columbia, Vancouver, BC

\section{Amélie Boutin PhD}

Postdoctoral fellow, Department of Obstetrics and Gynaecology, University of British Columbia, Vancouver, BC

\section{Sarka Lisonkova MD PhD}

Assistant professor, Department of Obstetrics and Gynaecology, University of British Columbia, Vancouver, BC

Cite as: CMAJ 2019 August 19;191:E922. doi: $10.1503 / \mathrm{cmaj} .72609$

\section{References}

1. Korb D, Goffinet F, Seco A, et al. for the EPIMOMS Study Group. Risk of severe maternal morbidity associated with cesarean delivery and the role of maternal age: a population-based propensity score analysis. CMAJ 2019;191:E352-60.

2. Hutton EK, Hannah ME, Willan A, et al.; Twin Birth Study Collaborative Group. Authors' reply re: Urinary stress incontinence and other maternal outcomes 2 years after caesarean or vaginal birth for twin pregnancy: a multicentre randomised trial. BJOG 2019;126:547.

3. Hannah ME, Hannah WJ, Hewson SA, et al. Planned caesarean section versus planned vaginal birth for breech presentation at term: a randomised multicentre trial. Term Breech Trial Collaborative Group. Lancet 2000;356:1375-83.

4. Barrett JF, Hannah ME, Hutton EK, et al.; Twin Birth Study Collaborative Group. A randomized trial of planned cesarean or vaginal delivery for twin pregnancy. N Engl J Med 2013;369:1295-305.

5. Joseph KS, Mehrabadi A, Lisonkova S. Confounding by indication and related concepts. Curr Epidemiol Rep 2014;1:1-8.

6. Liu S, Liston RM, Joseph KS, et al.; Maternal Health Study Group of the Canadian Perinatal Surveillance System. Maternal mortality and severe morbidity associated with low-risk planned cesarean delivery versus planned vaginal delivery at term. CMAJ 2007;176:455-60.

7. Silver RM, Landon MB, Rouse DJ, et al.; National Institute of Child Health and Human Development Maternal-Fetal Medicine Units Network.Maternal morbidity associated with multiple repeat cesarean deliveries. Obstet Gynecol 2006;107:1226-32.

Competing interests: None declared. 